\title{
Epidemiology and control of malaria in Colombia
}

\author{
Julio Cesar Padilla Rodríguez¹, Gilberto Álvarez Uribe', \\ Roberto Montoya Araújo², Pablo Chaparro Narváez ${ }^{3}$, Sócrates Herrera Valencia ${ }^{4,5}$ /+ \\ ${ }^{1}$ Ministry of Social Protection, Bogotá, Colombia \\ ${ }^{2}$ Pan American Health Organization, Bogotá, Colombia ${ }^{3}$ National Institute of Health, Bogotá, Colombia \\ ${ }^{4}$ Caucaseco Scientific Research Center, Cali, Colombia ${ }^{5}$ Centro Latino Americano de Investigación en Malaria, Cali, Colombia
}

\begin{abstract}
Malaria is currently one of the most serious public health problems in Colombia with an endemiclepidemic transmission pattern that has maintained endemic levels and an average of 105,000 annual clinical cases being reported over the last five years. Plasmodium vivax accounts for approximately $70 \%$ of reported cases with the remainder attributed almost exclusively to Plasmodium falciparum. A limited number of severe and complicated cases have resulted in mortality, which is a downward trend that has been maintained over the last few years. More than $90 \%$ of the malaria cases in Colombia are confined to 70 municipalities (about $7 \%$ of the total municipalities of Colombia), with high predominance (85\%) in rural areas. The purpose of this paper is to review the progress of malaria-eradication activities and control measures over the past century within the eco-epidemiologic context of malaria transmission together with official consolidated morbidity and mortality reports. This review may contribute to the formulation of new antimalarial strategies and policies intended to achieve malaria elimination/ eradication in Colombia and in the region.
\end{abstract}

Key words: Plasmodium falciparum - Plasmodium vivax -

endemic transmission - intervention measures - morbidity-mortality reports

Malaria remains one of the most serious public health problems worldwide with an estimated 1,382 billion people living in permanent risk of contracting the disease (Hay et al. 2009). About 243 million clinical cases are reported every year, resulting in an estimated 863,000 deaths, $89 \%$ of which occur in Africa (WHO 2009). In the American continent, malaria transmission occurs between southern Mexico and northern regions of Argentina (Carter 2009). It is estimated that at least $20 \%$ of the population living in the 21 countries is at risk of becoming ill and dying from malaria. The number of reported cases in the American continent decreased from 1,18 million in 2000 to 526,000 in 2009 (WHO 2010), which represents $0.5 \%$ of the global malaria burden (WHO 2009). Brazil and Colombia are the two most endemic countries in the continent, reporting more than $70 \%$ of the malaria cases; $\sim 70 \%$ of these cases are caused by Plasmodium vivax, with the remainder caused predominantly by Plasmodium falciparum and a small number of Plasmodium malariae cases. Although both $P$. falciparum and $P$. vivax contribute to mortality in the Latin American region, a limited number of deaths have been reported (109 cases in 2009) (WHO 2010).

In Colombia, malaria transmission presents an endemic/epidemic condition that maintains unstable endemic transmission levels throughout the country. The

Financial support: NIAID/NIH: TMRC (AI49486-01), ICEMR, CLAIM (U19AI089702)

+Corresponding author: sherrera@inmuno.org

Received 12 April 2011

Accepted 16 June 2011 tropical location and geographical characteristics of the country favour the existence of a diversity of geographic regions with a variety of climates and an abundance of anopheline vectors. Additionally, there is dynamic migration of infected human populations across the country, which contributes to the spread of disease and dissemination of drug-resistant malaria parasites (Arango et al. 2008). Malaria occurs mainly in areas with poor access to an already fragile healthcare system (Carter 2009).

A decreasing trend in clinical malaria cases has been reported over the past few years in Colombia with malaria cases falling from 144,432 in 2000 to 79,252 in 2009, therefore, Colombia is among the Latin American countries with a $25-50 \%$ reduction in malaria cases in the last decade along with Brazil and Guyana (WHO 2010). It may be noted that, according to the Epidemiologic Surveillance System (SIVIGILA), there was a new increase to 115,884 reported cases in 2010 . This increase was related to climatic variations, $70 \%$ was caused by $P$. vivax, and the remainder was almost exclusively caused by $P$. falciparum. However, in such regions as the Pacific coast, the $P$. vivax/P. falciparum ratio is reversed, due to the high prevalence of Afro-Colombian inhabitants and Duffy-negative individuals. The greater number of $P$. falciparum cases in these communities contributes to an increased frequency of malaria morbidity and mortality. Additionally, there are multiple small foci where $P$. malariae is transmitted with a prevalence of less than $0.05 \%$ (SIVIGILA 2011b).

Transmission is predominantly rural, but about $10 \%$ of the municipalities also have a high risk of peri-urban transmission; according to SIVIGILA, in 2008, $23 \mathrm{mu}-$ nicipalities registered 100 or more cases of urban malaria, which represents approximately $15 \%$ of malaria cases in 
the country. Transmission is strongly influenced by population migration associated with mining, timber/lumber industry, armed internal conflict and illicit agricultural activity (WHO 2005, Carter 2009). Most of the Colombian population is concentrated in the Andean Mountain region in cities more than 1,500 meters above sea level (masl) with sufficient sanitation and, therefore, little or no risk of malaria transmission. In the areas of highest malaria transmission, ecological diversity determines socioeconomic, cultural and political diversity and makes malaria transmission highly focal and variable (Yepes \& Quevedo 1990, MPS 2006). This phenomenon is aggravated by the concurrent presence of malaria parasites, multiple mosquito vectors and low levels of host immunity.

In this paper, we describe the eco-epidemiological conditions that favour malaria transmission in Colombia together with a review of official reports and epidemiological information on malaria morbidity and mortality from government records obtained from the Ministries of Social Protection, Agriculture and Environment, all of which are related to malaria control activities.

Epidemiology of malaria in Colombia - Malaria transmission in Colombia exhibits an unstable, endemicepidemic pattern of transmission with significant variability among the different transmission areas.

Although Colombia has a population estimated at 44,6 million inhabitants, most Colombians (> 70\%) live in large cities along the Andean Mountain region or in towns in which ecological conditions are not favourable for malaria transmission. It is estimated that approximately 10 million people (22\%) live in rural areas with a potential risk of malaria transmission, while two million people live in areas with high levels of transmission intensity [annual parasitic incidence (API) $>10$ cases $/ 1,000$ habitants]. Thus, $>90 \%$ of transmission occurs in rural localities, which are distributed in 70 of the more than 1,000 municipalities in the country (MPS 2008a). These figures indicate a significant concentration of malaria transmission in a limited population scattered over a wide geographic region.

Malaria transmission in Colombia: environmental considerations - Most Colombian territory is located north of the Equator in an inter-tropical zone and has variable altitudes ranging from 0-6,000 masl (Mantilla et al. 2009 , IGAC 2011). Approximately $70 \%$ of the territory has ecological conditions capable of supporting malaria transmission at an altitude under 1,600 masl (IGAC 2011).

Diverse geographic regions of the country, such as the Pacific and Caribbean coasts, the grassland plains and Orinoquia and the Amazonian Region, have predominant microepidemiologic and environmental features with adequate conditions for vector breeding and malaria transmission. Such features include tropical humid forest vegetation, low to dense forests, savannas, plains and valleys, wooded foothills, mountains and deserts (MS 1956). This geographic and ecological diversity strongly influences general social structures, as well as economic, political and cultural determinants, consequently resulting in a lifestyle promoting endemic and epidemic malaria transmission (Breilh 1979, Castellanos 1990).
The key variable that determines the intensity and prevalence of malaria is the migration of non-immune populations to endemic areas. Furthermore, the migration of infected, symptomatic individuals and asymptomatic parasite carriers from endemic areas to areas where malaria had been eliminated now present favourable ecological conditions for malaria transmission. Additionally, intense deforestation due to illicit agriculture and uncontrolled mining has favoured the establishment of mosquito breeding sites and the maintenance of high anopheline densities (MPS 2008b). Forty-one Anopheles species have been identified worldwide as primary vectors of $P$. falciparum and $P$. vivax (Sinka et al. 2010), but only a small number (Anopheles albimanus, Anopheles darlingi and Anopheles nuñeztovari) are widely distributed and considered primarily responsible for most of the malaria transmission in Colombia (Quiñones et al. 1987, Olano et al. 2001).

An. albimanus is distributed along the Pacific and $\mathrm{Ca}-$ ribbean coastal regions, generally at less than 500 masl. Although widely distributed in the region of Orinoquia (Meta, Vichada, Casanare), An. darlingi is also found on the Caribbean coast (Urabá, Nechí south Bolivar, Magdalena Medio), in the Amazon rainforest (Guaviare, Putumayo, Caquetá, Amazonas and Vaupés), and on the Pacific coast (Bajo Cauca). An. nuñeztovari is distributed in Catatumbo and Sararé Bajo, Cauca-Nechí, Urabá, Buenaventura and Magdalena Medio. Four other species, Anopheles punctimacula, Anopheles neivai, Anopheles lepidotus and Anopheles pseudopunctipennis, are considered to be of secondary importance (Quiñones et al. 1987, Villareal 1993). Recently, other species, including Anopheles (Nyssorhynchus) oswaldoi, Anopheles (N.) rangeli and Anopheles (N.) marajoara have been implicated as natural malaria vectors in Putumayo and Meta, respectively (Brochero et al. 2005, Ruiz et al. 2005).

Principal Colombian transmission areas - Despite its relatively wide range of malaria transmission, Colombia has four main transmission areas (Fig. 1): the region comprising Urabá, Sinu and Bajo Cauca which is located in the north-western region of the country, the Pacific coast, which is located in the western region, the Orino-

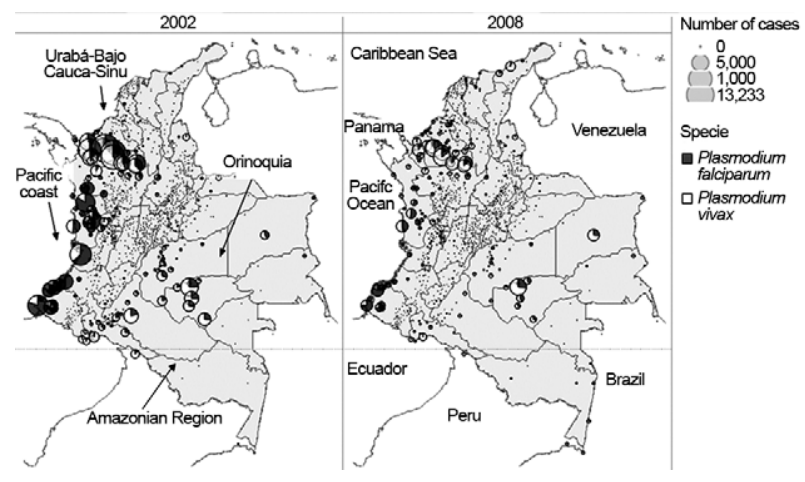

Fig. 1: malaria transmission foci in Colombia: evolution of the distribution of malaria cases in Colombia in 2002 and 2008 by Plasmodium species. 
quia, which is located in the eastern region, and the Amazonian Region, which is located in the southernmost region of Colombia adjacent to Brazil and Peru. Malaria transmission increased in Brazil in 2010; however, both Peru and Brazil have shown a decreasing trend in malaria cases over the past few years.

The Urabá-Sinu and Bajo Cauca - This region has an estimated area of $43,506 \mathrm{~km}^{2}$ and an at-risk population of 2,500,000 people distributed in 35 endemic municipalities from departments of Antioquia and Córdoba. This region is located near the Gulf of Urabá in Antioquia and extends to the Sinu River and the department of Córdoba. It has a warm and humid climate, especially in Bajo Cauca, and includes a wide expanse of plains and hills with altitudes between 0-200 masl. These geographical conditions and economic activities, such as mining, the banana agro-industry, cattle production and the timber industry, have provided a conducive environment for malaria transmission. Since the 1950s, this region has maintained a high malaria burden and predominance of $P$. vivax. According to reports of the National Institute of Health (NIH) of Colombia in 2010, the departments of Antioquia and Córdoba accounted for approximately $60 \%$ of the total cases in the country and represented the highest burden of malaria during this period. Córdoba contributes $18 \%$, mainly from the municipalities of Tierralta, Montelíbano and Puerto Libertador, whereas Antioquia contributes $42 \%$ of cases, which occur mainly in the municipalities of El Bagre, Cáceres and Zaragoza. SIVIGILA registered an API of 35.8/1,000 inhabitants for this region in 2010.

The Pacific coast - The region is one of the most endemic, characterized by a vast and humid rainforest populated mainly by Afro-Colombian and Indigenous communities that are scattered along the coastal forests. This region extends from the border of Panama (Gulf of Urabá) to the border with Ecuador with an estimated area of $71,508 \mathrm{Km}^{2}$, a mean temperature of $26^{\circ} \mathrm{C}$ and relatively high level of precipitation (3,000-10,000 mm); environmental conditions are highly suitable for malaria transmission. This region has accounted for $10-30 \%$ of malaria cases in Colombia in the last 50 years, concentrated in a population estimated at $5 \%$ of the total national population. It is considered the second most important location for malaria in the country. The region has two main transmission foci: one in the northern area, that includes the departments of Choco and Valle, and another in the southern area, that includes 10 coastal municipalities in Nariño and three in the department of Cauca. In the northern region, the population is mainly of African descent and has a high prevalence of haemoglobinopathies and Duffy-negative phenotypes and is thus refractory to P. vivax infection (MS 1997, Mendez \& Moyano 2005). This phenomenon results in a larger proportion of $P$. falciparum cases and a concomitantly higher risk of complicated malaria and mortality. In 2008, the Pacific region represented $24 \%$ of total malaria cases and $>50 \%$ of P. falciparum cases. Gold and platinum mining activities favour the presence of permanent mosquito breeding sites (Carmona 2003, 2004); in addition, fish farms are an important breeding source for Anopheles spp at the periphery of urban centres. Furthermore, the timber industry, subsistence agriculture, the recent proliferation of illicit crops and consequent internal conflicts have induced substantial forced displacement, contributing to the spread of malaria and endemic-epidemic transmission in this region (Padilla \& Peña 2002).

In some of these municipalities, a majority of cases have corresponded to urban malaria transmission, which is especially prevalent in the Pacific region with an average API of 73/1,000 inhabitants in the municipalities of department of Chocó between 1998-2008 (Mena 2009); however, there was a decline in API in 2010 to 14.6/1,000 inhabitants for this region that was related to control measures. In 2000, a study was conducted in Quibdó, the capital of department of Chocó, which showed that $39 \%$ of $P$. vivax cases and $24 \%$ of $P$. falciparum cases were of urban origin (Ochoa \& Osorio 2006).

The Orinoquia region - Originating in five municipalities from the departments of Arauca, Casanare, Guainía, Guaviare, Vichada and Meta, malaria transmission became increasingly prevalent in the mid-1980s, due to the proliferation and intensification of the cultivation of illicit crops followed by the settlement of illegal armed groups and consequent movement of the susceptible population (Molano 1987). This area is characterized by environmental degradation, inadequate housing, limited access to public services and health care and, particularly, migration of non-immune populations. The Orinoquia is a lowland region with considerable hydrographic sources that have provided mosquito breeding sites and ecological conditions for malaria transmission with an API of 6.8/1,000 inhabitants. The 2,419 reported malaria cases in this area represent approximately $2.1 \%$ of all Colombian cases (SIVIGILA 2011a).

The Amazon Region - This region comprises the departments of Amazonas, Caquetá, Guaviare, Putumayo and Vaupes. It covers an area of $483,000 \mathrm{~km}^{2}$ and includes $35 \%$ of the Colombian total territory of dense rainforest. The indigenous population is composed of numerous ethnic groups and a more limited number of immigrant settlers, who are most affected by malaria. However, due to its vast territorial expanse and low population density, the magnitude of the problem in this region is relatively less important with regard to total disease burden in the country; the API for this region in 2010 was $1.7 / 1,000$ inhabitants. A total of 6,605 malaria cases, or $5.7 \%$ of all cases, were reported in this area (SIVIGILA 2011a).

Malaria morbidity - Reports since the 1930s show that the lowest level of documented malaria cases in Colombia was in 1960 (Fig. 2) as a consequence of the worldwide Malaria Eradication Campaign. However, morbidity has steadily increased with a change in the prevalence of Plasmodium species. During this period, malaria has increased from approximately 9,000 cases in 1960 to a peak of 185,455 in 1998 (Carter 2009) and has decreased thereafter; during the last six years, $\sim 100,000$ malaria cases have been registered annually. In the 1960s and early 1970s, P. falciparum was the predominant spe- 
cies, presenting frequencies of approximately $60 \%$ from 1965-1973. Since 1974, P. vivax malaria has become predominant, except for a P. falciparum epidemic burst that occurred in 1998 when both parasite species presented similar incidences (Fig. 3). During the last decade (particularly in the last 5 years), there has been a reduction of P. falciparum to levels of $\sim 28 \%$ in 2008 , which is one of the lowest frequencies reported since 1960.

In the last seven years, a slow and modest decline in transmission was registered, which was probably attributable to improvements in diagnostic coverage and timely treatment. More recently, the introduction of artemisinin derivates combination therapy (ACT) in combination with a clear reduction in the extension of endemic areas as an outcome of different strategies for malaria control has resulted in a reduction in the at-risk population. A large number of municipalities (200-300) reported $<10$

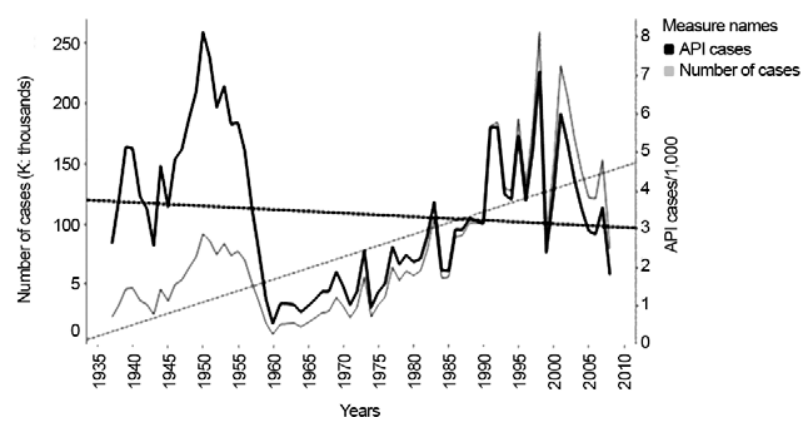

Fig. 2: number of malaria cases and incidence evolution, Colombia 1937-2008. API: annual parasitic incidence.
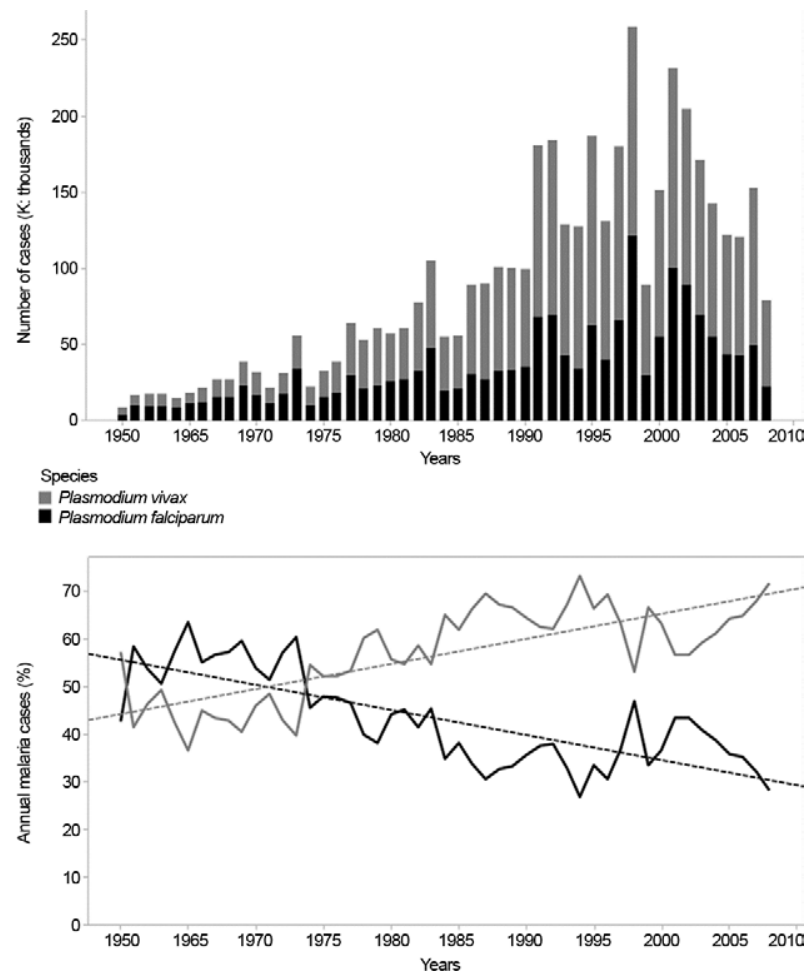

Fig. 3: distribution of malaria parasite species in Colombia, 1960-2008. malaria cases/year, whereas 20-40 registered $>1,000$ annual cases; $50 \%$ of the total cases derived from $13 \mathrm{mu}-$ nicipalities located in five departments (Fig. 4).

Regarding the target ages, young adults between 18-30 years of age are the most affected, probably due to occupational factors. In some regions, children under the age of 15 represent an important proportion of malaria morbidity, which is probably associated with intra and peri-domiciliary transmission. In 2008, paediatric malaria ranged from $15-44 \%$ (mean of $32 \%$ ) in different regions. Ethnic diversity, together with inherent cultural differences, also has contributed to significant changes in the transmission dynamics in different regions of the country.

Malaria mortality - Occurs mostly in people $<24$ years old, representing $\sim 40 \%$ of total malaria deaths. Children 1-4 years old contributed $14 \%$ of deaths, the age group younger than one year was responsible for $11 \%$ of deaths and people younger than 15 years old contributed $31 \%$ of total deaths from malaria in Colombia (Espinal et al. 1981).

Although there may be a degree of underreporting, malaria mortality has maintained a decreasing trend, primarily because of improvements in coverage and access to diagnosis and treatment in endemic priority areas. P. falciparum lethality declined from nine deaths $/ 1,000$ cases in the early 1980 s to less than one/1,000 cases in the last few years.
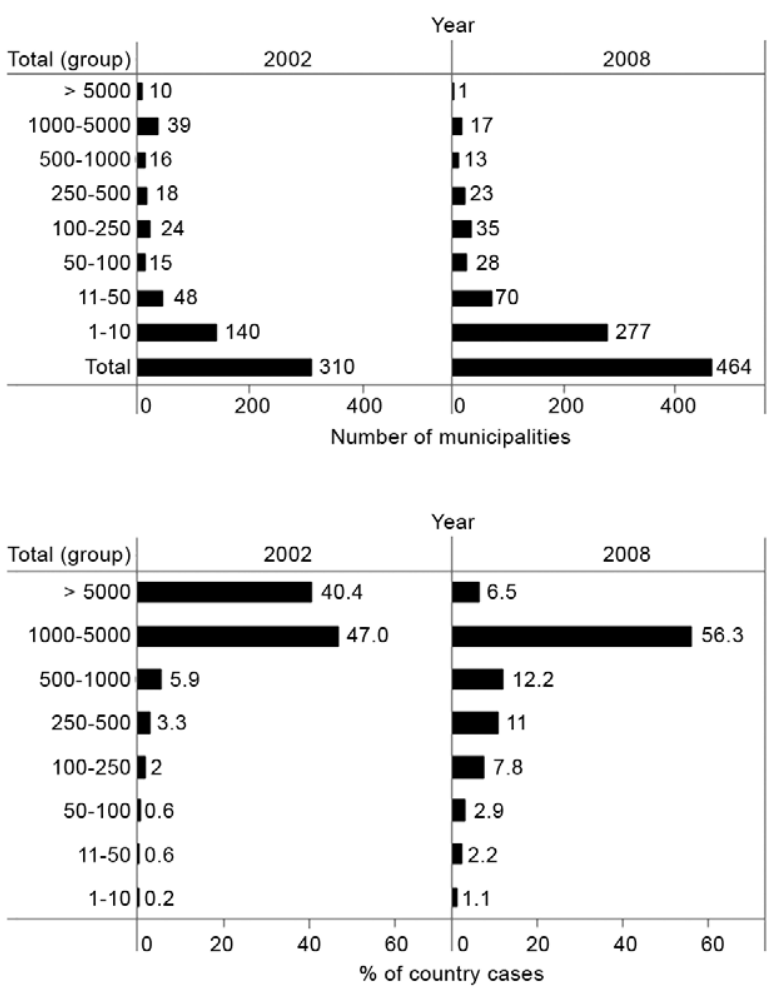

Fig. 4: distribution of municipalities in Colombia by malaria risk, 2002 and 2008: note that the group of municipalities with 1-10 cases increased from $45-59 \%$ between 2002-2008, as did the total number of municipalities. Regarding the percentage of total country cases, the groups of $>1,000$ cases accounted for $87 \%$ in 2002 and $62.8 \%$ in 2008 , showing a wider distribution of malaria burden throughout different groups of municipalities. 
According to the National Administrative Department of Statistics (DANE 2008), the number of deaths has decreased from 90 in 2005 to 55 in 2008; however, SIVIGILA has reported 20-60 deaths per year in the last three years and, regarding pregnant women, two deaths have been reported up to the 18th Epidemiologic Week in 2011. Although this number could be higher, considering the magnitude of the endemic and difficulties in access to services in high-risk regions, this number is of great concern for health services.

Information about Plasmodium species and complications of malaria related to mortality was provided by the Colombian NIH from 2008-2010. The distribution of complications was: cerebral malaria accounted for $48 \%$ of deaths and the remaining $52 \%$ was distributed between pulmonary, renal and hepatic complications. Approximately $48 \%$ of deaths corresponded to $P$. falciparum, $35 \%$ were of $P$. vivax, $15 \%$ were of mixed malaria and $2 \%$ were of $P$. malariae infections; however, it is possible that diagnostic errors of parasite species may have affected this distribution.

Control and elimination strategies - Colombian fight against malaria during the XX century - Colombia has invested significant efforts to control and eradicate malaria transmission since the first half of the past century. In the first half of the XX century, malaria control measures were aimed at improving sanitary conditions in sea, fluvial and land ports following the guidelines of the International Sanitary Conventions and Conferences and to offer appropriate means to maintain good trade conditions (Abel 1996, Hernandez \& Obregón 2002). Mosquito control campaigns were first initiated in certain ports and were subsequently extended to all cities. Malaria control activities during this period were concentrated in areas of major economic interest with the cooperation of international funding agencies, such as the Rockefeller Institute and Pan American Sanitary Bureau (República de Colombia 1920, 1922). In 1936, a campaign against malaria and uncinariasis was implemented through soil decontamination and, an year later, the systematic compilation of official malaria diagnostic records was initiated. By 1943, the Malariology Campaign was created in agreement with the International Cooperative Service of Public Health to promote antimalarial activities in the most endemic areas of the country. In 1947, this agency became the Malariology Division, which was in charge of sanitation activities that included the elimination of mosquito breeding sites, dichlorodiphenyltrichloroethane (DDT) spraying, distribution of antimalarial treatments and education (Hernandez \& Obregón 2002).

Since 1950, there has been an increased focus on the feasibility of eliminating mosquito breeding sites using strategies such as pond drainage and land-filling activities at the outskirts of villages. In addition, the discovery of synthetic antimalarials, documentation of the residual insecticide effects of DDT and the impact of sanitation measures have also increased the possibility of malaria elimination and eradication. In 1954, a Continental Plan for Malaria Eradication in the Americas was adopted by Colombia, consisting of the preparation and the attack phase (Nájera 1991). The Malaria Eradication Service was created in 1956, replacing the Malariology Division. During the preparation phase (1956-1958), the Service demonstrated that the number of malaria cases in Colombia was the highest in the American continent. Therefore, the attack phase of the Eradication Campaign was initiated with the goal of covering the entire malaria endemic area of the country with DDT spraying (SNEM 1963, 1971). Although the results were far from satisfactory, the campaign was extended until 1978, as the program was restructured and the control strategy initiated.

As shown in Fig. 5, during the National Malaria Control Program (NMCP) (1945-1978), malaria progression can be divided into three main phases. The first phase showed a rapid increase in malaria transmission in which $25,000-40,000$ cases were reported in the country at the beginning of the 1940 s, with a significant increase to over 75,000 cases by the beginning of the $1950 \mathrm{~s}$. The second phase consisted of a $50 \%$ reduction in malaria transmission at beginning of the campaign, due to eradication activities. Because of the appearance of $P$. falciparum resistance to chloroquine (CQ) in 1960 (Moore \& Lanier 1961, Espinal et al. 1981) and mosquito resistance to DDT in 1952 (Livadas \& Georgopoulos 1953), along with a reduction in investments for antimalarial activities, a change in the elimination pattern was observed (Fig. 5). Since 1960, a third phase of malaria transmission appeared in which a general upward trend in malaria morbidity has been seen (SNEM 1971).

After an analysis of the malaria eradication program in the Americas by Pan American Health Organization (PAHO) at the end of 1979, Colombia, along with El Salvador, Guatemala, Haiti, Honduras, Nicaragua and Peru, was classified in a group in which the immediate objective consisted of reducing mortality and morbidity (OPS 1980). This objective was to be achieved by targeting areas in which transmission persisted and additionally aimed to avoid malaria resurgence in areas where malaria had already been eliminated. By 1979, malaria rates were steadily climbing (OMS 1979); 14 years later (1993), the incidence of malaria had more than doubled (Mendez \& Carrasquilla 1995).

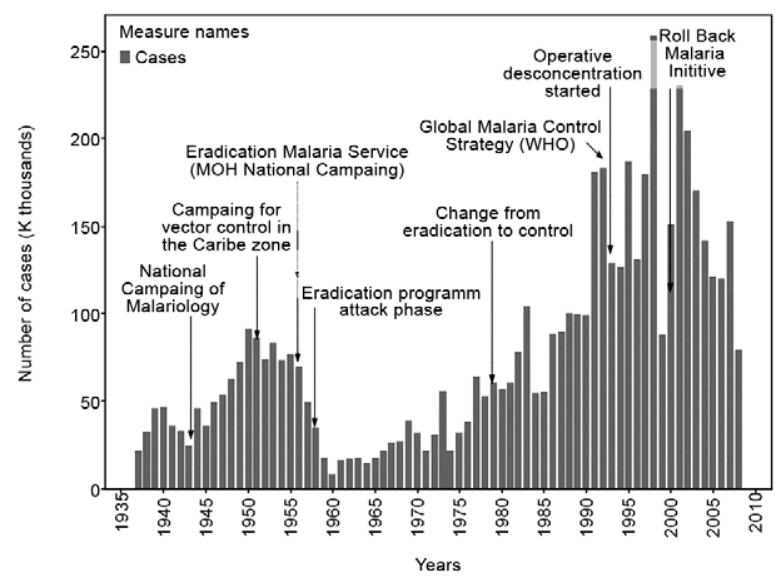

Fig. 5: evolution of malaria cases according to the malaria control/ eradication strategy between 1937-2008. 
A centralized malaria-control policy was maintained until 1993 when an operative decentralization of the campaign was initiated based on the principles of the Global Malaria Control Strategy (GMCS) (WHO 1993, Padilla 1997). In 2000, the operative strategy of Roll Back Malaria was adopted and a program of institutional strengthening to improve technical and institutional responses was initiated. Unfortunately, the situation continued to deteriorate. As shown in Fig. 5, during the 1990s, incidence rates were comparable to those of the 1940s and 1950s.

In addition to the several institutions belonging to various ministries mentioned above, recent control and surveillance activities have had significant participation by the Colombian NIH, particularly the SIVIGILA. Additional participation included the following entities: the Ministry of Agriculture and Employment, the inhabitants report from DANE, entomological reports from the Colombian NIH, control and interventions from NMCP and participation of communities and individuals at risk as part of integrated malaria control programs (Kroeger et al. 1996, Rojas et al. 2001).

Diagnosis and treatment strategies - During the past 15 years, Colombia has adhered to the principles of the GMCS. Malaria treatment has been limited to cases with passive and active parasitological diagnosis by thick blood smears. The treatment policy has consisted of radical cure and schemes for $P$. falciparum have included the use of primaquine and combination therapies (Young \& Moore 1961).

In 2008, the index of positive films (proportion of thick positive films among all films examined) was $17 \%$, a figure lower than that recorded in previous years in which the annual index ranged from $23 \%$ in 2007 to $31 \%$ in 2001 (Fig. 6). A total of $66.2 \%$ of malaria cases recorded by the malaria surveillance system had access to diagnosis within $72 \mathrm{~h}$ of symptoms onset; this figure is related mainly to difficulties in access to health facilities, poverty and armed conflict. Appropriate therapeutic policies on early treatment are the main determinant of success for control measures. For P. falciparum malaria, initiating treatment before the appearance of gametocytes (7-10 days after the onset of symptoms) is a key strategic point in the interruption of transmission. However, malaria treatment is included in the package of health services in which the purchase and distribution of medications to the regions is centralized and dependent on the Ministry of Social Protection (MPS). Although private health systems are also involved in malaria diagnosis and early treatment, the situation is particularly complicated in endemic areas that are difficult to access and exhibit a high level of population dispersion.

In 1961, CQ resistance was first reported in Colombia. Since 1981, many other antimalarial drug treatment failures have been reported (Osorio et al. 1997, López et al. 1999, Blair-Trujillo et al. 2002, González et al. 2003). Although the response to treatment with sulfadoxine/pyrimethamine (SP) has been better in Colombia compared with other countries in the Amazon Region, failure rates ranging between $6-15 \%$ have also been documented, mainly in the Bajo Cauca and Pacific coast regions (González et al. 2003). In the late 1990s,
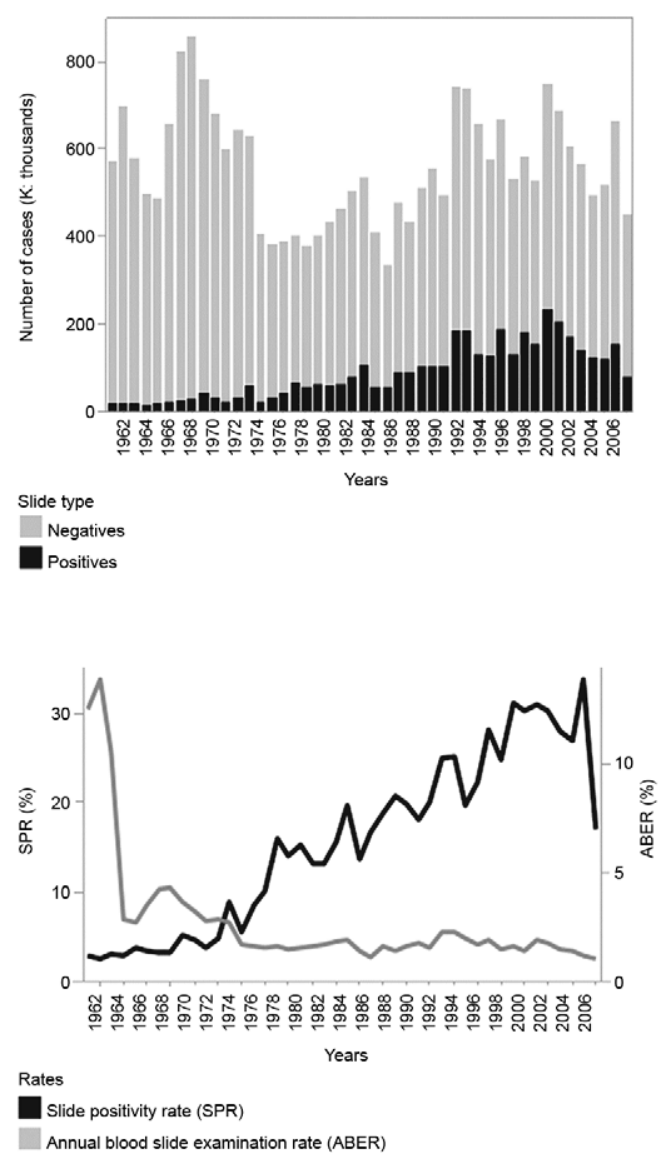

Fig. 6: malaria slide positivity rate in Colombia between 1962-2008.

the treatment scheme changed from $\mathrm{CQ}+\mathrm{SP}$ to amodiaquine $(\mathrm{AQ})+\mathrm{SP}$, due to high resistance to $\mathrm{CQ}$. The policy was assessed in 2001 and the analysis showed levels of treatment failure of $10.8 \%$ in a study conducted in the Pacific coast region (Gonzalez 2004). According to WHO recommendations and based on a treatment failure for AQ monotherapy of about $50 \%$ with a follow-up of 28 days and 7-12\% with a follow-up of 14 days (MPS 2007), the MPS introduced the use of ACT for P. falciparum non-complicated malaria in 2006 (MPS 2007). The Amazon Network for Monitoring Antimalarial Resistance (RAVREDA), which was coordinated by PAHO with the participation of the eight Amazonian countries and funded by United States Agency for International Development (USAID) between 2002-2006, promoted the introduction of ACT in all countries of this subregion (RAVREDA-AMI 2009). In the past several years, a significant reduction in the number of cases of malaria attributed to $P$. falciparum has been shown in several departments, especially in the Pacific coast, where the combination of artemether (ATM) and lumefantrine (LUM) has been used (Fig. 7). According to national guidelines, the current first-line treatment in Colombia for uncomplicated P. falciparum cases is still ATM + LUM; in the case of $P$. vivax infections, the treatment is 


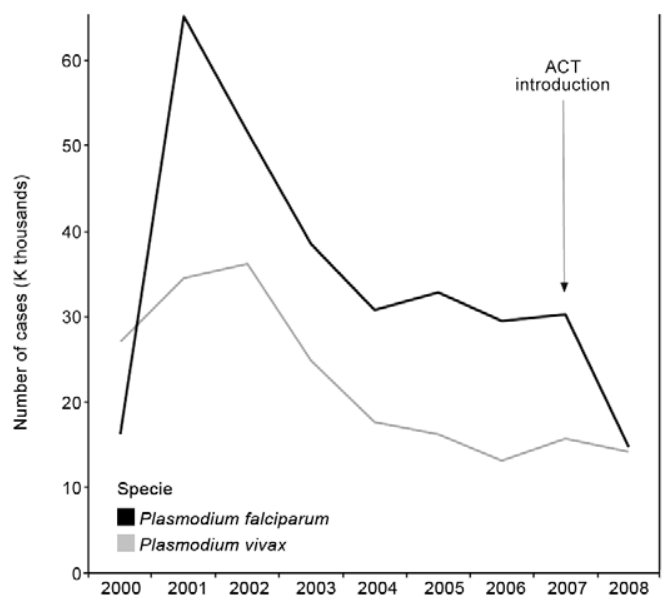

Fig. 7: number of malaria cases in the Pacific coast, Colombia 20002008: malaria trend related to Plasmodium species and introduction of artemisinin derivates combination therapy (ACT).

$\mathrm{CQ}+$ primaquine for erythrocytic and tissular forms. In Colombia, CQ remains highly effective against $P$. vivax and, is therefore, still the first-line treatment, despite resistance reports from Papua New Guinea, Peru and Brazil (OPS/OMS-MPS 2010). Although malaria intervention activities have included other measures, such as the use of long-lasting impregnated nets (LLIN), the reduction has also been influenced by concurrent climate changes that have affected disease transmission characteristics across the region and, in the last few years, a significant reduction in the number of cases was observed: 180,956 cases in 2003 decreased to 79,252 cases in 2009 (WHO 2010).

Perspectives - Malaria is considered a serious public health problem in Colombia, primarily due to the number of malaria cases that are mainly caused by $P$. vivax infection. Focal and variable transmission has been modified by the interaction between structural socioeconomic, political and cultural influences developed in variable eco-epidemiologic scenarios. In addition, the geographic features of the territory favour widespread transmission. Social problems in rural areas, which have persisted over the last 50 years, promote the transmission of malaria and adversely affect malaria control efforts.

The malaria control measures implemented in Colombia over different periods have achieved important reductions in mortality. Encouraging results were obtained with the use of CQ therapy and DTT spraying during malaria eradication campaigns, but multidrug resistance forced changes in malaria control strategies.

Although such strategies have had an important impact on malaria control in Colombia, there is a need to find solutions to the problem of health care for poor and underserved populations, where malaria is simply one of many other public health problems.

The strategy of selective control, primarily involving the ability to stratify and prioritize actions, along with an understanding of the dynamics of transmission according to GMCS, has never been properly adopted. Changes in the health system have failed to strengthen capacity at local levels. Moreover, there has been a negative impact regarding technical aspects, such as the inappropriate use of residual spraying, high operative costs, incomplete interventions in urban areas with high population densities and disease burdens, and lack of information about residual insecticides on walls and nets, all of which enable decision-making at the local and central levels.

Notwithstanding these challenges, a series of actions have contributed to a reduction of the disease via the availability of highly effective tools against $P$. falciparum, such as the introduction of artemisinin derivatives and the use of ACT and LLIN. For P. vivax infection, intervention by identifying at-risk families and individuals within localities and the implementation of intensive-focused interventions with preventive measures and treatment involving patients and relatives within the house has resulted in an almost $50 \%$ reduction of malaria cases between 2007-2008. However, reducing the time between symptoms onset and treatment initiation remains a major challenge in many high-risk municipalities. New surveillance strategies as part of the heath system recently adopted in the country have allowed monitoring of effectiveness at the municipality level in communities and health facilities. This is expected to improve management in the coming years and to increase the participation of communities and individuals at risk.

Therefore, improvements in diagnosis and treatment, knowledge of local transmission characteristics, active case detection with positive blood films, identification of populations at risk, enhancement of detection by the use of rapid diagnostic tests, early treatment and the use of LLIN are all to be included in future planning to improve malaria control in Colombia. Such experimental learning has been based on international cooperation from the Control de la Malaria en las Zonas Fronterizas de la Región Andina: un Enfoque Comunitario (PAMAFRO) Project, PAHO coordination with USAID funds, which support the consolidation of RAVREDA, the Centro Latinoamericano para la Investigación y Control de la Malaria (CLAIM), which is sponsored by US National Institute of Allergy and Infectious Diseases, the Colombian MPS and NIH.

\section{ACKNOWLEDGEMENTS}

To the Colombian Ministry of Social Protection, to WHO/ TDR Special Programme, to the National Institute of Allergy and Infectious Diseases, to the Centro Latinoamericano para la Investigación y Control de la Malaria, for the support and encouragement provided by in producing this review, and to Dr Mark James and Dr Vanessa Ocampo, for critical review of the manuscript.

\section{REFERENCES}

Abel C 1996. Ensayos de historia de la salud en Colombia, 19201990, Universidad Nacional de Colombia, Editorial CEREC, Bogota, $142 \mathrm{pp}$.

Arango E, Carmona-Fonseca J, Blair S 2008. In vitro susceptibility of Colombian Plasmodium falciparum isolates to different antimalarial drugs. Biomedica 2: 213-223.

Blair-Trujillo S, Lacharme-Lora L, Carmona-Fonseca J 2002. Resistance of Plasmodium falciparum to antimalarial drugs in Zaragoza (Antioquia, Colombia), 1998. Mem Inst Oswaldo Cruz 97: 401-406. 
Breilh J 1979. Epidemiologia, economía, medicina y politica, Universidad Central, Quito, $127 \mathrm{pp}$.

Brochero HL, Rey G, Buitrago LS, Olano VA 2005. Biting activity and breeding sites of Anopheles species in the municipality Villavicencio, Meta, Colombia. J Am Mosq Control Assoc 21: 182-186.

Carmona J 2003. La malaria en Colombia, Antioquia y las zonas de Urabá y Bajo Cauca: panorama para interpretar la falla terapéutica antimalárica. Parte 1. Iatreia 16: 4.

Carmona J 2004. La malaria en Colombia, Antioquia y las zonas de Urabá y Bajo Cauca: panorama para interpretar la falla terapéutica antimalárica. Parte 2. Iatreia 17: 1.

Carter K 2009. Report on situation of malaria in the Americas, 2008. Available from: new.paho.org/hq/index.php?option $=$ com conten t\&task= view\&id=2459\&Itemid $=2049$.

Castellanos PL 1990. Sobre el concepto de salud enfermedad. Descripción y explicación de la situación de salud. Bol Epidemiol Ofic Panam Sanit 10: 1-74.

DANE - Departamento Administrativo Nacional de Estadística 2008. Estadísticas Vitales 2005-2008, Bogota. Available from: dane. gov.co/daneweb_V09/index.php?option=com_content\&view=art icle $\&$ id $=73 \&$ Itemid $=119$.

Espinal C, Uribe L, Eslava A, Rodríguez M 1981. Resistencia del Plasmodium falciparum a la combinación sulfa-pirimetamina. Biomedica 1: 213-217.

González I 2004. Evaluación de la eficacia terapéutica y de la seguridad de la combinación de amodiaquina y sulfadoxina/pirimetamina en el tratamiento de malaria no complicada por Plasmodium falciparum en el municipio de Tadó, Chocó, en la costa pacífica colombiana. In Programa de pequeños subsidios en enfermedades tropicales. Informes Finales, Organización Panamericana de la Salud 2004. Available from: paho.org/Spanish/AD/DPC/CD/res-grants.htm.

González I, Padilla JC, Giraldo LE, Saravia N 2003. Eficacia de amodiaquina y sulfadoxina/pirimetamina en el tratamiento de la malaria no complicada por Plasmodium falciparum en Nariño, Colombia 1999-2002. Biomedica 23: 38-46.

Hay SI, Guerra CA, Gething PW, Patil AP, Tatem AJ, Noor AM, Kabaria CW, Manh BH, Elyazar IR, Brooker S, Smith DL, Moyeed RA, Snow RW 2009. A world malaria map: Plasmodium falciparum endemicity in 2007. PLoS Med 6: e1000048.

Hernandez M, Obregón D 2002. La OPS y el estado colombiano: cien años de historia. 1902-2002, Organización Panamericana de la Salud, Bogota, 442 pp.

IGAC - Instituto Geografico Agustin Codazzi 2011. República de Colombia [database on the Internet]. 2011 [cited Marzo 17 de 2011]. unique. Available from: igac.gov.co:10040/wps/portal/ igac/raiz/iniciohome.

Kroeger A, Meyer R, Mancheno M, González M 1996. Health education for community-based malaria control: an intervention study in Ecuador, Colombia and Nicaragua. Trop Med Int Health 1: 836-846.

Livadas GA, Georgopoulos G 1953. Development of resistance to DDT by Anopheles sacharovi in Greece. Bull World Health Organ 8: 497-511.

López Y, Arroyave A, Salazar A 1999. Evaluación de la resistencia in vivo a los medicamentos antimaláricos, El Bagre, Antioquia, 1998. Rev Epid Antioquia 24: 181-194.

Magill AJ, Zegarra J, Garcia C, Marquiño W, Ruebush TK 2004. Efficacy of sulfadoxine - pyrimethamine and mefloquine for treatment of uncomplicated Plasmodium falciparum malaria in the Amazon basin of Peru. Rev Soc Bras Med Trop 37: 279-281.

Mantilla G, Oliveros H, Barnston A 2009. The role of ENSO in understanding changes in Colombia's annual malaria burden by region, 1960-2006. Malaria J 8: 6.
Mena Y 2009. Caracterización del comportamiento de la malaria en el departamento de Chocó durante el periodo 1998-2008, PhD Thesis, Universidad CES, Medellín, 47 pp.

Mendez F, Carrasquilla G 1995. Epidemiología de la malaria en el área urbana de Buenaventura: análisis de la ocurrencia en el periodo 1987-1993. Colomb Med 26: 77-85.

Mendez F, Moyano M 2005. Defectos eritrocíticos y densidad de la parasitemia en pacientes con malaria por $P$. falciparum en Buenaventura, Colombia. Rev Panam Salud Publica 18: 25-32.

Molano A 1987. Selva adentro. Una historia oral de la colonización del Guaviare, El Áncora, Bogota, 138 pp.

Montoya R 2008. Gestión de redes en la OPS/OMS Brasil: conceptos, prácticas y lecciones aprendidas, Organización Panamericana de la Salud, Brasilia, 182 pp.

Moore D, Lanier S 1961. Observations on two Plasmodium infections with an abnormal response to chloroquine. Am J Trop Med Hyg 10: 5-9.

MPS - Ministerio de la Protección Social 2006. Situación de la malaria en Colombia 2006: Informe a la OPS/OMS, Dirección General de Salud Pública, Bogota.

MPS - Ministerio de la Protección Social 2007. Plan de implementación de combinación terapéutica con derivados de la artemisinina (CTD) en áreas de alta transmisión de Colombia, Dirección General de Salud Pública, Bogota.

MPS - Ministerio de la Protección Social 2008a. Informe situación de la malaria en Colombia, Direccion General de Salud Publica, Bogota.

MPS - Ministerio de la Protección Social 2008b. Malaria y objetivos de desarrollo del milenio, Bogota.

MS - Ministerio de Salud Pública de Colombia 1956. Plan de erradicación de la malaria, Tomo 1, Bogota.

MS - Ministerio de Salud/Instituto Nacional de Salud De Colombia 1997. Hemoglobinopatías en Colombia. IQEN 2: 171.

Nájera JA 1991. El paludismo y otras actividades de la Organización Mundial de la Salud. Bol Of Sanit Panam 111: 131-151.

Ochoa J, Osorio L 2006. Epidemiología de la malaria urbana en Quibdo, Chocó. Biomedica 26: 278-285.

Olano V, Brochero H, Saenz R, Quiñones M, Molina J 2001. Mapas preliminares de la distribución de especies de Anopheles vectores de malaria en Colombia. Biomedica 21: 402-408.

OMS - Organización Mundial de Salud 1979. Informe del comité de revisión y evaluación al programa de Malaria. In Organización Mundial de la Salud/Organización Panamericana de la Salud/ Ministerio de Salud de Colombia, OMS, Bogota.

OPS - Organización Panamericana de la Salud 1980. Situación de los programas de erradicación de la malaria. Organización Panamericana de la Salud. Boletín Epidemiologico 1, 6: 1-16.

OPS/OMS-MPS - Organización Panamericana de la Salud/Organización Mundial de Salud-Ministerio de la Protección Social 2010. Guia de atencion clinica de malaria (documento actualizado de version convenio 256/09), Ministerio de la Proteccion Social, Bogota, $132 \mathrm{pp}$.

Osorio L, Giraldo L, Grajales L, Barat L, Córdoba F, Arriaga A 1997. Evaluación in vivo de la resistencia de Plasmodium falciparum a cloroquina y sulfa/pirimetamina en Quibdo, Choco. Biomedica 17: 201-202.

Padilla 1997. Implementación de la estrategia de control de la malaria en Colombia. Biomedica 17 (Suppl. 2).

Padilla J, Peña S 2002. Situacion de la malaria en Colombia en 2002. Informe epidemiologico, Subdirección de Vigilancia/Instituto Nacional de Salud, Bogota. 
Quiñones ML, Suarez MF, Fleming G 1987. Estado de la susceptibilidad al DDT de los principales vectores de malaria en Colombia y su implicacion epidemiologica. Biomedica 7: 81-86.

RAVREDA-AMI - Amazon Network for the Surveillance of Antimalarial Drug Resistance RAVREDA-Amazon Malaria Initiative. Pan American Health Organization 2009. [database on the Internet] [cited Sept 20 de 2010]. Available from: paho.org/English/ $\mathrm{AD} / \mathrm{DPC} / \mathrm{CD} /$ ravreda-ami.htm.

República de Colombia 1920. Acuerdo $N^{\circ} 76$ de 1920. Desinfecciones urbanas. Concejo Municipal de Bogota.

República de Colombia 1922. Ley 99 de 1922, Congreso de Colombia, Bogota.

Rojas W, Botero S, Garcia HI 2001. An integrated malaria control program with community participation on the Pacific Coast of Colombia. Cad Saude Publica 17: 103-113.

Ruiz F, Quiñones ML, Erazo HF, Calle DA, Alzate JF, Linton YM 2005. Molecular differentiation of Anopheles (Nyssorhynchus) benarrochi and An. (N.) oswaldoi from Southern Colombia. Mem Inst Oswaldo Cruz 100: 155-160.

Sinka ME, Rubio-Palis Y, Manguin S, Patil AP, Temperley WH, Gething PW, Van Boeckel T, Kabaria CW, Harbach RE, Hay SI 2010. The dominant Anopheles vectors of human malaria in the Americas: occurrence data, distribution maps and bionomic précis. Parasit Vectors 3: 72.

SIVIGILA 2011a. Comportamiento de la Malaria en Colombia según los casos notificados al SIVIGILA durante 2010. Corte 2 febrero 2011. Grupo ETV, Instituto Nacional de Salud, Bogota, 5 pp.

SIVIGILA 2011b. Sistema de vigilancia epidemiológica. Boletín vigilancia de la malaria en Colombia 52: 12.
SNEM - Servicios Nacionales de Erradicación de la Malaria 1963. III Reunión de directores de los Servicios Nacionales de Erradicación de la Malaria en América del Sur. Informe final, SNEM, Bogota.

SNEM - Servicios Nacionales de Erradicación de la Malaria 1971. Reunión de directores de los SNEM en las Américas, Informe final, SNEM, San Salvador.

Villareal LI 1993. Situación actual de la vigilancia entomológica de la resistencia a los insecticidas en Colombia. Taller teóricopráctico: técnicas de evaluación de susceptibilidad y resistencia de mosquitos a insecticidas, Medellín.

WHO - World Health Organization 1993. Implementation of global malaria control strategy: report of a WHO study group on the imprementation of the global plan of action for malaria control 1993-2000. Tech Rep Ser 839: 1-57.

WHO - World Health Organization 2005. World malaria report, WHO, Geneva. Available from: who.int/malaria/publications/ atoz/9241593199/en/index.html.

WHO - World Health Organization 2009. World malaria report 2009, WHO, Geneva. Available from: who.int/malaria/world_malaria_ report 2009/en/index.html.

WHO - World Health Organization 2010. World malaria report, WHO, Geneva, Available from: who.int/malaria/world malaria report_2010/en/index.html.

Yepes FJ, Quevedo E 1990. La salud en Colombia: análisis socioeconómico. Estudio sectorial de Salud, Ministerio de Salud/Departamento Nacional de Planeación, Bogota.

Young M, Moore D 1961. Chloroquine resistance in Plasmodium falciparum. Am J Trop Med Hyg 10: 317-320. 